\title{
Thermal investigation on HSPM with new alloy sleeve
}

\author{
Xiaochen. Zhang ${ }^{1,2}$, Weili. Li ${ }^{1}$, He. Zhang ${ }^{3 *}$, Chris. Gerada ${ }^{2,3}$, David. Gerada ${ }^{2}$, Jing. Li ${ }^{2}$ \\ ${ }^{1}$ School of Electrical Engineering, Beijing Jiaotong University, China \\ ${ }^{2}$ Department of Electrical and Electronic Engineering, The University of Nottingham, UK \\ ${ }^{3}$ IAMET, University of Nottingham, China \\ Email: he.zhang@nottingham.edu.cn ${ }^{3}$
}

\begin{abstract}
This paper presents a developed copper-iron alloy which made as the rotor sleeve in a high speed permanent magnetic machine (HSPMG), whist investigating its benefits in improve machine thermal performance. The features of the new alloy is experimental tested against the performance, which includes the conductivity, the permeability, and thermal conductivity, and the variation of loss distribution inside machine with sleeve conductivity and permeability are studied. A fluid-thermal coupled analysis model is proposed, by using which the fluid velocity and temperature distribution are obtained via numerical analyzing. The variations of machine operating temperature with new material are evaluated.
\end{abstract}

Index Terms-- HSPM, Alloy, Thermal, Coupling analyses, Performance.

\section{INTRODUCTION}

The micro turbine generation system is one of most important and popular distributed generation system (DGS) due to its flexibility and high efficiency, currently it is becoming a main development stream in DGS gradually. The high speed permanent magnetic generator (HSPMG) is often adopted in a micro turbine generation system due to high efficiency, high power density, simple structure, and high reliability [1][2]. However, HSPMG normally requires a metal or carbon fiber rotor sleeve to retain the surface mounted magnets because of enormous centrifugal force during the high speed operation. Metal rotor sleeve are often favorable due to its simplicity and cost, but also pay the penalty of high eddy current loss and high rotor temperature.

The operating frequency in a HSPMG is relatively high, and the higher order harmonics in the air-gap flux increases eddy current loss in metal rotor sleeve [3]. Thus, both the resistivity and permeability of the sleeve material affect generator magnetic circuit and losses directly. From the thermal management point of view, the sleeve is the main thermal path for the heat generated in rotor to be transferred to stator side, the sleeve thermal conductivity effects rotor operating temperature, and the safety and reliability of magnets in HSPMG. Therefore, the electrical magnetic and thermal characteristics of rotor sleeve are critical and require careful selection during HSPMG design stage.

The electrical magnetic and thermal properties of the material are optimized for rotor sleeve application with the development of material manufacturing and nanocomposites, Iron-copper alloy is one of the most suitable material for rotor sleeve, the electric, mechanical and thermal properties changes via adding other elements, changing the crystal structures, or changing the manufacturing processes [4].

In this paper, a newly developed alloy mainly made of iron and copper is applied in a $100 \mathrm{~kW}$ level HSPMG. Considering effects of sleeve material characteristics on both the magnetic circuit and heat transfer paths comprehensively, the output and thermal performance of HSPMG with new sleeve is studied based on electromagnetic-fluid-thermal coupled analysis, based on which the variations of machine rotor losses and operating temperature with rotor sleeve characteristics are established.

\section{Development of Iron-COPPER alloy}

To reduce large flux leakage in the rotor sleeve, the preferable material for rotor sleeve would have lower permeability, and have high mechanical strength and high thermal conductivity. A novel type of iron-copper alloy is developed to serve such requires.

The alloy is mainly composed of industrial pure iron $(79.1 \%$ in weight) and electrolytic copper $(20 \%$ in weight), and the other trace elements with weight percentage of $0.9 \%$. For using different mark of iron, the Carbon weight percentage are different, and this leads to the variation of magnetic permeability. In this study three alloys have carbon proportion of $0.017 \%$ (No.I), $0.16 \%$ (No.II), and $0.36 \%$ (No.III) are processed and studied, which are made in both as-cast and anneal states.

The make-up of the copper-iron alloy and its tissue photograph scanned by an FEI Sirsion 2000 high-power microscope is shown in Fig. 1. In the iron-copper alloy microstructure, the ferrite crystal grains are covered with $\mathrm{Cu}$, and there is no metallic compound generated in the process of alloy smelting, which makes the binding force between $\mathrm{Fe}$ and $\mathrm{Cu}$ is very weak, so the toughness of iron-copper alloy is relatively weak. The main organizations of these two elements are ferritic and net, semi-net and semi-island states. As the increase of Carbon proportion, pearlites among matrix material are increasing gradually, and its magnetic conductivity strengthens, whereas the electric conductivity decreases. With increase of Carbon proportion, the as-cast and annealed state ironcopper alloy rock well hardness increases gradually. For the as-cast alloys, the impact toughness is small and with no significant differences, thus such alloys belong to brittle material. Whereas for annealing state alloy, the impact toughness increases significantly Carbon content, and the impact toughness decreases. 


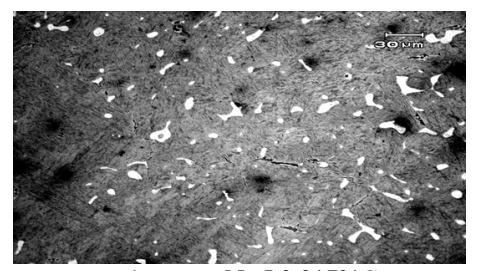

a) as-cast No.I $0.017 \% \mathrm{C}$

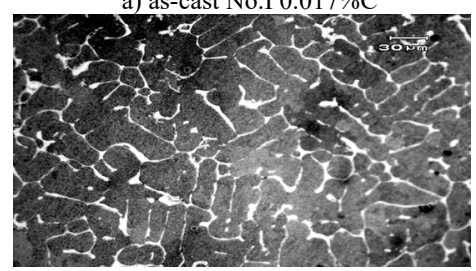

d) annealed No.I $0.017 \% \mathrm{C}$

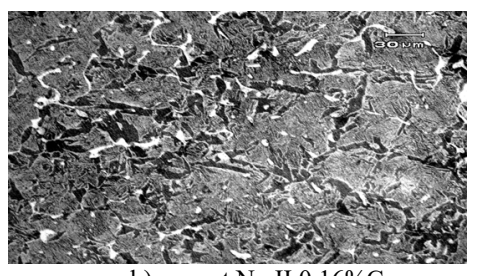

b) as-cast No.II $0.16 \% \mathrm{C}$

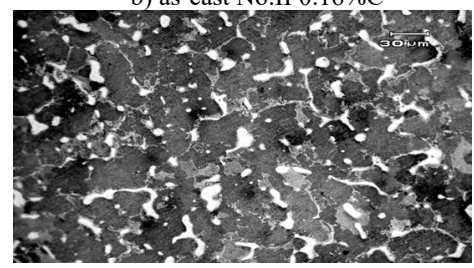

e) annealed No.II $0.16 \% \mathrm{C}$

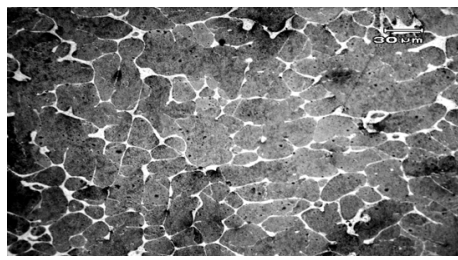

c) as-cast No.III $0.36 \% \mathrm{C}$

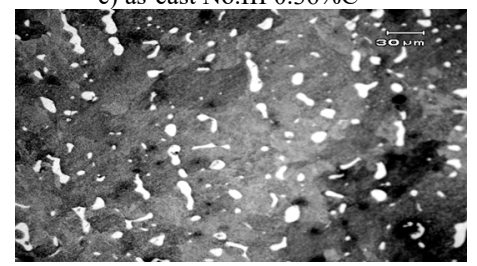

f) annealed No.III $0.36 \% \mathrm{C}$

Fig. 1 Microstructures of iron-copper alloys with different Carbon proportions.

TABLE I

THE MEASURED CONDUCTIVITY OF IRON-COPPER ALLOY

\begin{tabular}{|c|c|c|c|}
\hline \multirow{2}{*}{ Alloy No. } & \multicolumn{2}{|c|}{ conductivity(S/m) } & Relative Permeability \\
\cline { 2 - 3 } & as-cast & annealed & H=200Gs \\
\hline I & $6.42 \mathrm{e}+06$ & $6.93 \mathrm{e}+06$ & 1.162 \\
\hline II & $6.01 \mathrm{e}+06$ & $6.48 \mathrm{e}+06$ & 1.483 \\
\hline III & $5.52 \mathrm{e}+06$ & $5.89 \mathrm{e}+06$ & 1.737 \\
\hline
\end{tabular}

The conductivity and the permeability of the copperiron alloy are measured. The results are listed in Table. I. The thermal conductivity of the alloys are also tested, which indicates that all the alloy sample have almost the same thermal conductivity, which is around $68.7 \mathrm{~W} /\left(\mathrm{m}{ }^{\circ} \mathrm{C}\right)$ at $20^{\circ} \mathrm{C}$.

\section{INFLUENCE OF ALLOY MATERIAL CHARACTERISTICS ON HSPMG POERFORMANCE}

The sleeves made of the three different alloy are used in a $117 \mathrm{~kW}$ HSPMG for comparison with slender structure used in MTGS. Its rated operating speed is $60000 \mathrm{rpm}$; the rated output voltage is $670 \mathrm{v}$; the core length is $275 \mathrm{~mm}$; the outer diameter of the stator is 135 $\mathrm{mm}$. The prototype and inside structure are shown in Fig.2. The rotor is excited by the permanent magnets (PM) which are protected by a metal sleeve. The magnets are made of SM-26U, with magnetic retentivity of $1.05 \mathrm{~T}$ and magnetic coercivity of $750 \mathrm{kA} / \mathrm{m}$, and the maximum operating temperature is $350^{\circ} \mathrm{C}$.

\section{A. Electromagnetic analysis and loss determination}

Since a slender structure is adopted and there is no skew in the machine, distribution of flux density is considered invariably along the axial direction in this HSPMG[5]. Therefore only two-dimensional (2D) cross section is considered to analysis the electromagnetic field, as is shown in Fig. 2.

In order to simplify the analysis model, only space harmonics caused by the machine structure are considered in the analysis. From the transient electromagnetic analysis, the flux distributions of the machine are obtained, and the flux in HSPMG with different rotor sleeve is comparatively analyzed. Fig. 3 shows the flux distribution in HSPMG with different sleeve. In the machine with iron-copper alloy sleeve, the pole-pole flux

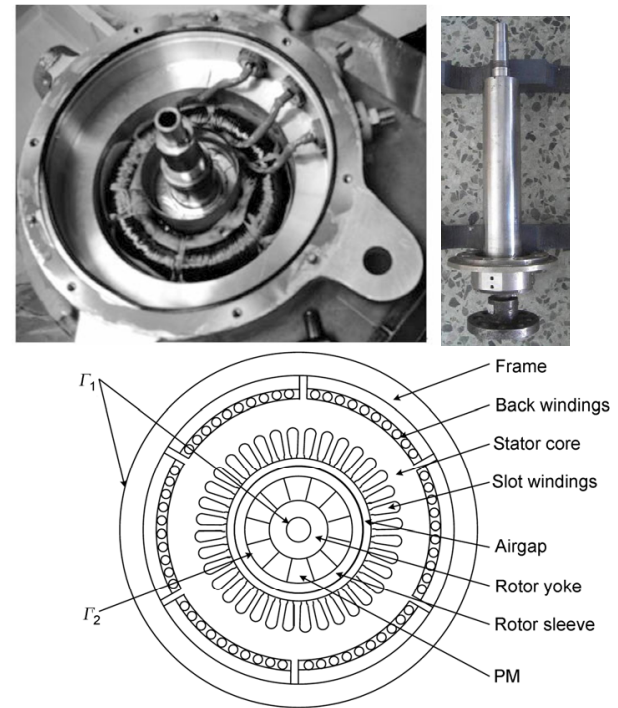

Fig. 2. Prototype and structure of HSPMG.

leakage is relatively big, because of its high permeability more flux is looped in sleeve. Although the flux provided by $\mathrm{PM}$ increase about $22 \%$, the main flux in air-gap is only $87 \%$ of that in machine with non-magnetic sleeve. The detail data are list in Table II.
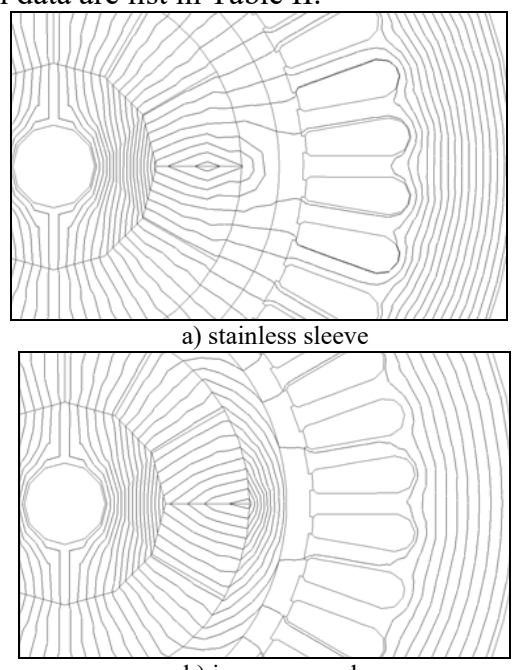

b) iron-copper sleeve

Fig. 3. Flux distribution in HSPMG with different rotor sleeve. 
TABLE II

FLUX PROVIDED BY PERMANENT MAGNET AND MAIN MAGNETIC FLUX

\begin{tabular}{|c|c|c|c|c|}
\hline \multirow{2}{*}{$\begin{array}{c}\text { Flux } \\
\left(10^{-3} \mathrm{~Wb}\right)\end{array}$} & \multicolumn{4}{|c|}{ sleeve material } \\
\cline { 2 - 5 } & stainless & Carbon fiber & $\begin{array}{c}\text { Iron-copper } \\
\text { alloy }\end{array}$ & copper \\
\hline PM & 11.70 & 11.72 & 15.02 & 11.72 \\
\hline Air-gap & 10.01 & 10.02 & 8.78 & 10.06 \\
\hline
\end{tabular}

By using the method mentioned in [6], the eddy current loss in rotor sleeve is calculated. The variation of loss with sleeve conductivity and permeability are evaluated respectively. Fig. 4 shows the stator core loss and rotor eddy loss in HSPMG with different sleeve, in which the eddy loss is caused as the eddy current in the sleeve due to conductivity. Then for the reduction of eddy current density distributed area, the eddy loss is decreasing gradually. The maximum eddy loss appears when sleeve has conductivity of $2.5 \times 10^{6} \mathrm{~S} / \mathrm{m}$, which can be significantly reduced with the new alloy material.

As the increasing of sleeve permeability, the magnetic resistance in main flux circuit is reduced, and the main flux increases, result in more core loss in the stator. However, with the permeability continued to increase, pole-pole flux leakage increases as well and again the main magnetic flux decreases, which results in less stator core loss. The variation curve of stator core loss as sleeve permeability is present in Fig. 5. It can be present in the figure that the variation trend of rotor eddy loss is the same as that of stator core loss and the main reasons lead to such change are the skin depth and the harmonics in air-gap.

According to [7], the friction loss on the rotor outer surface is determined as $466 \mathrm{~W}$. Besides, with the electromagnetic losses obtained from the above analyses, the loss distribution in HSPMG under rated operating is determined, as shown in Table III, are the distributed heat generation sources.

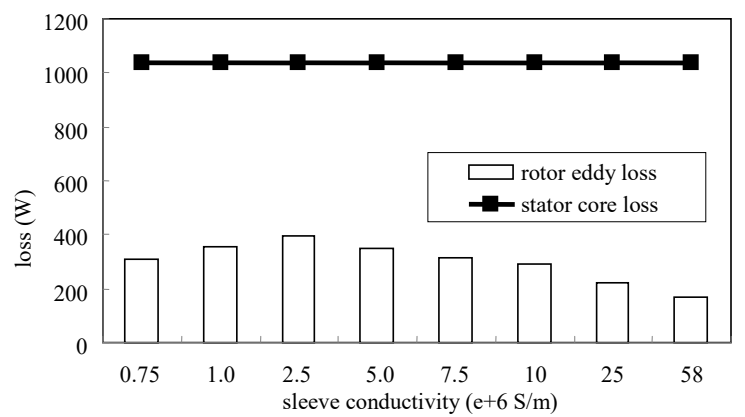

Fig. 4. Variation of the generator losses with different conductivity sleeves.

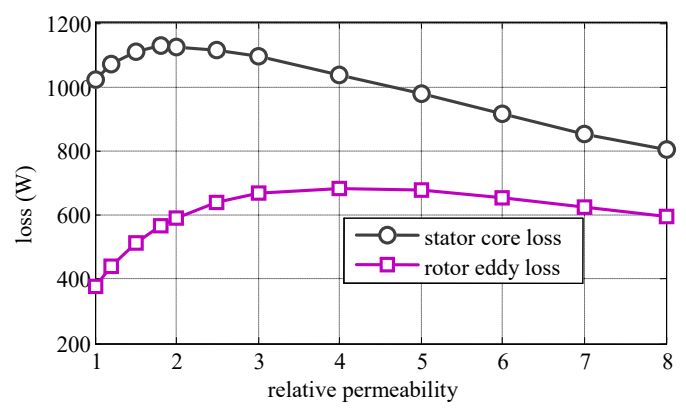

Fig. 5. Variation of generator losses with sleeve relative permeability,
TABLE III

COMPARISON OF RESULTS FROM NUMERICAL CALCULATION AND ANALYTICAL METHOD

\begin{tabular}{|l|r|r|r|}
\hline & Analytical & Numerical & error \\
\hline Armature current (in A) & 36.1 & 36.3 & $0.5 \%$ \\
\hline Terminal Voltage (line in V) & 480 & 479.5 & $-0.1 \%$ \\
\hline Output power (in kVA) & 30 & 30.1 & $0.3 \%$ \\
\hline Total iron loss (in W) & 453.36 & 442.75 & $-3 \%$ \\
\hline Copper loss (in W) & 229.5 & 233 & $1.5 \%$ \\
\hline Rotor eddy loss (in W) & ------ & 396.7 & ------- \\
\hline
\end{tabular}

\section{B. Fluid-thermal coupled analysis}

The machine adopts a closed oil cooling system, and there is an oil separator (epoxy resin board) in the air-gap adjacent to the stator core inner surface and end closures to ensure oil-tight closure on the stator side. The cooling medium flows through the stator slot grooves and the yoke back space along the axial direction. Thus, stator windings and core are cooled directly. The windings and cooling system structure are shown in Fig. 6.

Considering the structure symmetry, the whole region of the machine (including stator and rotor) with one pole phase is selected as the 3D fluid-thermal coupling analysis model [8], as shown in Fig. 7, in which the heat generations of the end windings are considered in the core length region. In the fluid region (Fig. 7(b)), the mass flow boundary condition is applied to the fluid inlet, and at the calculation region outer surfaces $\left(S_{1}\right)$, it satisfies the thermal insulation boundary. For the solid region (Fig. $7(\mathrm{c})$ ), the interface between rotor and shaft and the tooth center surfaces along the axial direction $\left(S_{2}\right)$ meet the adiabatic boundary. For the frame outer surface $\left(S_{3}\right)$, there is only natural heat convection.

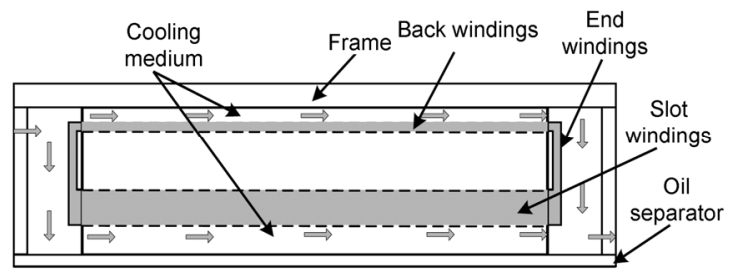

Fig. 6. Windings and cooling system structure in HSPMG.

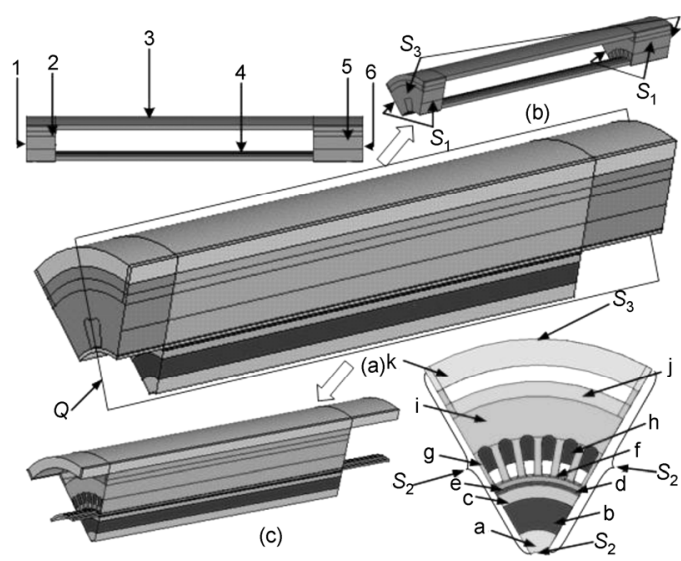

Fig. 7. Calculation regions for $3 \mathrm{D}$ fluid-thermal coupling analysis. 1, Fluid inlet; 2, inlet end fluid; 3, fluid in yoke back room; 4, fluid in slot grooves; 5, outlet end fluid; 6, outlet. a, Rotor yoke; b, PM; c, sleeve; d, air-gap; e, oil separator; f, tooth-top; g, tooth; h, equivalent windings; I, yoke; $j$, back windings; $k$, frame. 


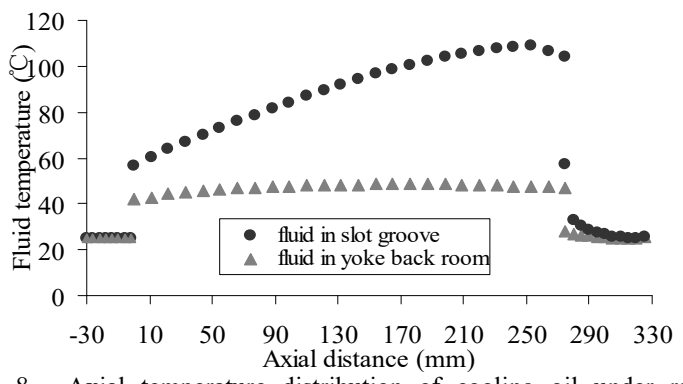

Fig. 8. Axial temperature distribution of cooling oil under rated operating.

From the fluid-thermal coupled analysis, the whole region 3-D temperature distribution is obtained. The axial temperature distribution of fluid in the cooling system is shown in Fig.8. In the stator core length region (0$275 \mathrm{~mm}$ ), the temperature of fluid in contact with the stator core changes significantly along the axial direction, and it rises from $57{ }^{\circ} \mathrm{C}$ to $109{ }^{\circ} \mathrm{C}$. Throughout the fluid in the stator back yoke space, however, the temperature is distributed more evenly, with axial differences less than 2 ${ }^{\circ} \mathrm{C}$. Due to the boundary layer effects, after the mixed in the end rooms, the outlet fluid temperature is much lower as shown in Fig. 8.

Fig. 9 shows the temperature distribution in solid region. Due to the poor heat transfer capacity of the air in air-gap, the stator cooling system has little influence on the rotor, thus the highest temperature inside this domain appears in the rotor, which is about $236{ }^{\circ} \mathrm{C}$. The stator region temperature varies widely between $97{ }^{\circ} \mathrm{C}$ and 133 ${ }^{\circ} \mathrm{C}$ due to the directly cooling oil through the stator. In the machine with iron-copper sleeve, the highest operating temperature reaches $264^{\circ} \mathrm{C}$, while in both case, the temperature distribution remains similar.

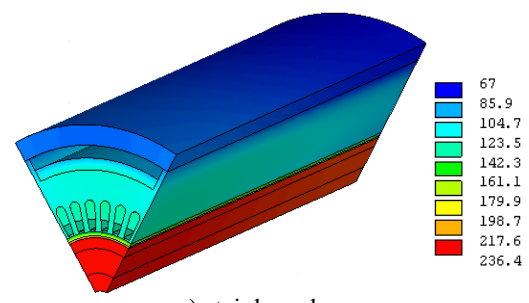

a) stainless sleeve

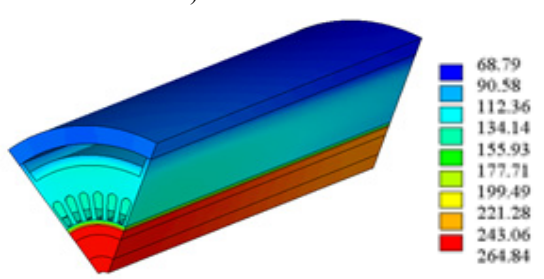

b) iron-copper sleeve

Fig. 9. 3-D temperature distribution in solid region of analysis model.

In this study, the inlet and the outlet temperatures of cooling oil are measured while the machine operates with no-load under different speeds. During the process, the oil flow rate is kept at $1.624 \mathrm{~m}^{3} / \mathrm{h}$. Comparisons of the calculated results with the measured data are shown in Table IV, where the calculated results strongly agree with the measured data.
Table. V shows the variation of the HSPMG component operating temperature with sleeve conductivity. As the sleeve conductivity increases, the operating temperatures of machine different locations decrease, because of the reduction of the eddy loss in the sleeve. However, the highest temperature always locates at rotor magnets, which is $0.5^{\circ} \mathrm{C}$ higher than that of the sleeve. Whereas, the terminal voltage and the output power increases as the sleeve permeability increases. With the increasing of losses, the highest temperature also increases. Thus, an alloy with high thermal conductivity is beneficial to reduce the operating temperature.

Fig. 10 shows the variations of out power, the phase voltage, and the highest operating temperature with sleeve permeability. With the increase of sleeve permeability, the changes of the highest operating temperature reach $31 \%$, which is much larger than that of HSPMG output power and phase voltage.

TABLE IV

COMPARISON OF CALCULATED TEMPERATURES WITH THE TEST DATA UNDER DiFFERENT OPERATING SitUATION $\left({ }^{\circ} \mathrm{C}\right)$

\begin{tabular}{|c|c|c|c|c|c|}
\hline \multicolumn{2}{|c|}{ operating } & \multicolumn{3}{c|}{ Measured } & Calculated \\
\hline \multirow{2}{*}{$\begin{array}{c}\text { Non-load } \\
\text { cooling oil }\end{array}$} & $\begin{array}{c}\text { speed } \\
\text { r/min }\end{array}$ & inlet & outlet & $\begin{array}{c}\text { Temperature } \\
\text { rise }\end{array}$ & $\begin{array}{c}\text { Temperature } \\
\text { rise }\end{array}$ \\
\cline { 2 - 6 } temperature & 21000 & 19.0 & 19.4 & 0.4 & 0.45 \\
\cline { 2 - 6 } & 36000 & 16.7 & 17.7 & 1.0 & 0.95 \\
\cline { 2 - 6 } & 48000 & 21.9 & 23.5 & 1.6 & 1.7 \\
\hline
\end{tabular}

TABLE IV

AVERAGE TEMPERATURE OF THE GENERATOR WITH DIFFERENT CONDUCTIVITY SLEEVES $\left({ }^{\circ} \mathrm{C}\right)$

\begin{tabular}{|c|c|c|c|c|}
\hline $\begin{array}{c}\text { Conductivity } \\
\left(10^{6} \mathrm{~S} / \mathrm{m}\right)\end{array}$ & magnets & sleeve & Air gap & $\begin{array}{c}\text { Stator } \\
\text { core }\end{array}$ \\
\hline 0.75 & 215.8 & 215.5 & 203.0 & 123.0 \\
\hline 1 & 225.5 & 225.2 & 221.1 & 124.4 \\
\hline 2.5 & 235.6 & 235.5 & 219.7 & 125.9 \\
\hline 5 & 225.1 & 225.1 & 211.0 & 124.4 \\
\hline 7.5 & 217.8 & 217.8 & 204.9 & 123.4 \\
\hline 10 & 213.3 & 213.3 & 201.2 & 122.7 \\
\hline 25 & 193.9 & 194.0 & 185.1 & 119.8 \\
\hline 58 & 183.8 & 183.9 & 176.7 & 118.4 \\
\hline
\end{tabular}

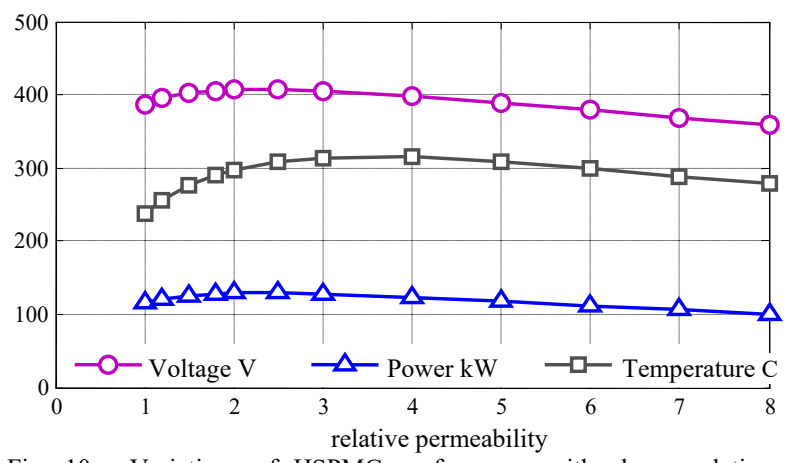

Fig. 10. Variations of HSPMG performance with sleeve relative permeability.

\section{CONClusions}

Because of the increase of the output power, stator copper loss increases rapidly, lead to high operating temperature. Although increase sleeve permeability can increase the output voltage and power of the motor within 
a certain range, but in the highest temperature of motor will be further increased. So for the determination of sleeve permeability in alloy design, the maximum operating temperature should be ensured within the limited one while enhance machine electromagnetic performance.

\section{ACKNOWLEDGMENT}

This work is supported by the National Natural Science Foundation of China under Grant 51407006.

\section{REFERENCES}

[1] H. Do-Kwan, W. Byung-Chul, L. Ji-Young, K. Dae-Hyun. "Ultra High Speed Motor Supported by Air Foil Bearings for Air Blower Cooling Fuel Cells". IEEE Trans. on Magn., 2012, Vol. 48, No. 2, pp. 871-874.

[2] J. Zhu, Y. Guo, Z. Lin, et al. "Development of PM transverse flux motors with soft magnetic composite cores". IEEE Trans. Magn. 2011, vol. 47 , no. 10 , pp. $4376-4383$.

[3] D. Hong, J. Choi, D. Kim, et al. "Development of a high speed induction motor for spindle systems". IEEE Trans. Magn., 2013, 49(7), 4088-4091.

[4] T. Waeckerle, R. Batonnet, T. Wery, F. Petit. "Fully Processed FeCo Soft Magnetic Laminations for High-Speed Electrical Machines". IEEE Trans. on Magn., 2014, Vol. 50, No. 1, \#: 2002606.

[5] X. Zhang, W. Li, B. Kou, , et al. "Electro-thermal combined optimization on notch in air cooled High Speed Permanent Magnetic Generator", IEEE Trans. Magn. 2015, Vol. 51, No. 1, \# 8200210 .

[6] S. Niu, S. L. Ho, W. N. Fu, Z. Jian Guo. "Eddy Current Reduction in High-Speed Machines and Eddy Current Loss Analysis with Multi slice Time-Stepping Finite-Element Method”. IEEE Trans. on Magn., 2012, Vol. 48, No. 2, pp. 1007-1010.

[7] C. Huynh, Z. Liping, D. Acharya, "Losses in high speed permanent magnet machines used in microturbine applications". Journal of Engineering for Gas Turbines and Power, vol. 131 /022301-1-6, Mar. 2009.

[8] L. Weili, Z. Xiaochen, C. Shukang, and C. Junci. "Thermal Optimization for a HSPMG Used for Distributed Generation Systems", IEEE Trans. Ind. Electron., 2013, vol. 60, no. 2, pp.474482. 